\title{
The Underground Main Fan Study atthe Waste Isolation Pilot Plant
}

\author{
Kirk H. McDaniel ${ }^{\text {I }}$ K.M. (Chris) Chmura ${ }^{2}$, Keith G. Wallace ${ }^{3}$

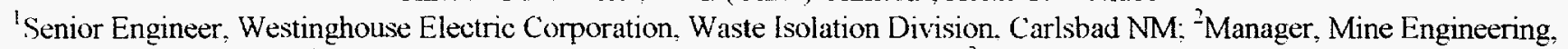 \\ Westinghouse Electric Corporation. Waste Isolation Division. Carlsbad, NM: ${ }^{3}$ Vice President, Mine Ventilation Services, Inc., \\ Fresno, CA.
}

\begin{abstract}
The Waste Isolation Pilot Plant (WIPP) performed a feasibility analysis for the purpose of either modifying, supplementing, or replacing its two main mine fans. The WIPP, located near Carlsbad, New Mexico, is a U.S. Department of Energy (DOE) facility designed to demonstrate the permanent, safe disposal of U.S. defense-generated transuranic waste in a deep bedded salt deposit.
\end{abstract}

Since the centrifugal fans were installed in 1988, multiple operational and performance concerns have been identified. A comprehensive engineering study was conducted in 1995 to: 1) Qualify and quantify operational concerns, 2) Evaluate possible alternatives, and 3) Recommend an optimum solution.

Multiple system modification and/or replacement scenarios were evaluated with associated cost estimates developed. The study considered replacement with either centrifugal or axial fans. Multiple fan duties are required at the WIPP. Therefore, Variable Frequency Drives and Inlet Vane Controls (IVC) were investigated for centrifugal fans. In-flight adjustable blades were investigated for axial fans.

The study indicated that replacing the existing system with two double-width, double-inlet centrifugal fans equipped with IVCs was the best choice. This alternative provided the most desirable combination of: 1) ensuring the required operational readiness, and 2) improving system performance. The WIPP is currently planning to replace the first fan in 1997.

\section{OVERVIEW OF THE WASTE ISOLATION PILOT PLANT}

The Waste Isolation Pilot Plant (WIPP) is designed to permanently dispose of transuranic radioactive waste left from the research and production of muclear weapons. The WIPP is located in southeastern New Mexico 43 kilometers (26 miles) east of Carlsbad. Project facilities include disposal rooms excavated in an ancient (approximately 250 million years old), stable salt formation 660 $\mathrm{m}(2150 \mathrm{ft})$ underground. Transuranic waste consists of clothing, tools, rags, and other such items contaminated with trace amounts of radioactive elements, mostly plutonium.

\section{DESCRIPTION OF THE VENTILATION SYSTEM}

Ventilation of the underground facility at WIPP is accomplished with four main ventilation splits called the north area, mining area, waste storage area, and the waste shaft station. In order to minimize occupational exposure of underground personnel to radiation and radioactive materials, the facility is designed and constructed based on the "As Low As Reasonably Achievable" (ALARA) concept. This concept resulted in a design where the nuclear waste transportation and storage areas are separated from the mining 


\section{DISCLAMMER}

Portions of this document may be illegible in electronic image products. Images are produced from the best available original document. 


\section{DISCLAIMER}

This report was prepared as an account of work sponsored by an agency of the United States Government. Neither the United States Goverament nor any agency thereof, nor any of their employees, make any warranty, express or implied, or asumes any legal liability or responsibility for the accuracy, completeness, or usefulness of any information, apparatus, product, or process disclosed, or represents that its use would not infringe privately owned rights. Reference herein to any specific commercial product, process, or service by trade name, trademark, manufacturer, or otherwise does not necessarily constitute or imply its endorsement, recommendation, or favoring by the United States Government or any agency thereof. The views and opinions of authors expressed herein do not necessarily state or reflect those of the United States Government or any agency thereof. 
This document has been reproduced directly from the best possible copy.

It is available to DOE and DOE contractors at the following addresses:

Office of Scientific and Technical Information

P.O. Box 62

Oak Ridge, TN 37831

Prices available from (615) 576-8401

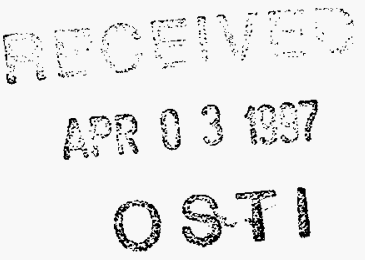

Available to the public from the National Technical Information Services

U. S. Department of Commerce

5285 Port Royal Road

Springfield, VA 22161

Processing and final preparation of this report was performed by the Waste Isolation Pilot Plant Management and Operating Contractor for the U.S. Department of Energy under Contract No. DE-ACO4-86AL31950. 
and non-radioactive experimental areas. The ventilation system is also designed such that air leakage is from the mining and north areas into the waste storage areas. Furthermore, radiation detectors are strategically located throughout the underground, and a contingent exhaust filtration system is installed on surface to minimize the unlikely release of radiation to the environment.

The underground facility is accessed and ventilated through four vertical shafts, three of which supply intake air, and the fourth acts as a common exhaust. Ventilation through the facility is provided by running either one or both $450 \mathrm{~kW}$ ( $600 \mathrm{hp}$ ) centrifugal main fans. During concurrent mining and waste handling operations, both fans operate in parallel (Normal Ventilation Mode) to provide $230 \mathrm{~m}^{3} / \mathrm{s}(490,000 \mathrm{acfm})$. When either mining or waste emplacement is not taking place, the ventilation demand is decreased and only one main fan is operated (Alternate Ventilation Mode) resulting in an airflow of $140 \mathrm{~m}^{3} / \mathrm{s}(300,000 \mathrm{actm})$. In the unlikely event of an underground radioactive release, the ventilation system is shifted to a filtration mode. In Filtration Mode, the air flow is reduced to $28 \mathrm{~m}^{3} / \mathrm{s}(60,000 \mathrm{acfm})$. This airflow is achieved by turning off the main fans and starting one of three $175 \mathrm{~kW}(235 \mathrm{hp})$ centrifugal stand-by filtration fans. A series of isolation dampers diverts the air through the High Efficiency Particulate Air (HEPA) filters.

\section{THE MAIN FAN STUDY}

The main fans were installed in 1988 to supply the WIPP facility with the capability of conducting simultaneous mining and waste emplacement activities. Their design was based primarily on: 1) accepted ventilation engineering principles, 2) the best available data and calculations from the ventilation system, 3) current knowledge of the underground environment, and 4) the design parameters of interfacing WIPP structures. Field measured data collected since then has documented that some of the original design assumptions did not accurately reflect real operating conditions. The result is that the main fan system does not operate well in the environment for which is was originally designed. These factors have contributed to multiple operational and performance concerns. The key concerns associated with the performance of the main fan system include:

1) premature failure of a fan wheel.

2) 7 to 8 years expected operation between major overhauls.

3) demonstrated poor ability to endure weathering in a corrosive sait-and-moisture environment.

4) unequal power consumption between fans.

5) Operational Readiness (OR) of $65 \%$ in Normal Ventilation Mode.

6) fan static efficiency of $55 \%$ in Normal Ventilation Mode, as compared to the original design efficiency requirement of $85 \%$.

7) concern that the present system mav not effectively support simultaneous mining and waste emplacement at fully operational levels.

8) no system redundancy in Normal Ventilation Mode.

From August 1994 through July 1995, the Mine Engineering Group of WIPP/ Westinghouse Electric Co. conducted a comprehensive engineering study of the underground ventilation main fan system. This study was undertaken in an attempt to: 1) qualify and quantify the operational difficulties experienced with the fans since their installation, 2) evaluate possible alternatives, and 3) recommend a 
solution that would optimize the main fan configuration.

The current fan system was thoroughly evaluated as part of the study. The identified deficiencies were fully investigated through field inspection and testing of the fans. Engineering calculations, maintenance records, and historical operational availability data on the fans were also evaluated. The current physical condition and performance characteristics were documented, as well as alternatives for repairing and/or improving the fans.

The scenario of keeping the existing fans and overhauling them on a periodic basis became the base case for the study. A series of svstem modification and/or replacement alternatives which would satisfy the operational needs of the facility were developed. Each șstem was judged against predetermined acceptance criteria of: 1) capital cost, 2) power consumption savings, and 3) $O R$.

The alternatives which passed these criteria were augmented by supplementary Life Cycle Cost Analyses for the purpose of obtaining In House Energy Management (IHEM) funding for the project. IHEM is a U.S. Department of Energy program which finances projects based on their energy cost savings. These alternatives were compared against the base case.

The most favorable scenarios were evaluated to determine Present Value, Net Savings, Power Savings, Simple Payback, Savings-toInvestment Ratio, and Adjusted Internal Rate of Return for both ten and twenty-five year operational periods (these concepts are not discussed in this paper). In addition, they were evaluated to consider the flexibility and possible operational impacts associated with the alternative(s). The following section discusses the evaluation process for the main fan study.

\section{EVALUATION OF EXISTING FANS AND CONCLUSIONS}

The first step in the main fan study involved a thorough evaluation of both existing fans, including a review of their historical performance data. This information was obtained from field testing, review of operator logs and lockout/tagout records, and a review of the fans' design and performance characteristics.

The evaluation lead to the following conclusions: 1) stated concerns and field observations were confirmed, and 2) the existing fans could not be sufficiently modified to adequately address all of the concerns. The results of this evaluation were summarized in the report called "Underground Main Ventilation Fan Study Report" - May 1995. In order to secure the required performance of the main fan system, it was recommended to upgrade the existing system through implementation of one of the preferred scenarios.

\section{EVALUATION CRITERIA AND METHODOLOGY}

The evaluation methodology considered the capital cost, power consumption, and $O R$ for each alternative. The scenarios considered for the system upgrade consisted of combinations of either replacing the two existing fans, adding a third fan, or repairing the existing fans. A comparative analysis was performed to eliminate alternatives from further consideration based on pass/fail selection criteria. Three pass/fail criteria were selected to reflect reasonable expectations of capital cost and operating characteristics. Figure 1 shows 
the logic sequence associated with the evaluation and screening of multiple fan scenarios using the pass/fail criteria. Options were considered valid if the estimated replacement cost did not exceed $\$ 1,300,000$. This value was considered a reasonable cost which could be incurred without violating funding criteria for this type of project. Power consumption savings for each alternative had to be greater than $600,000 \mathrm{kWhr} / \mathrm{yr}$ (as compared to the existing fans). This value was considered a reasonable improvement in the power consumption as a benefit for replacing the fans.

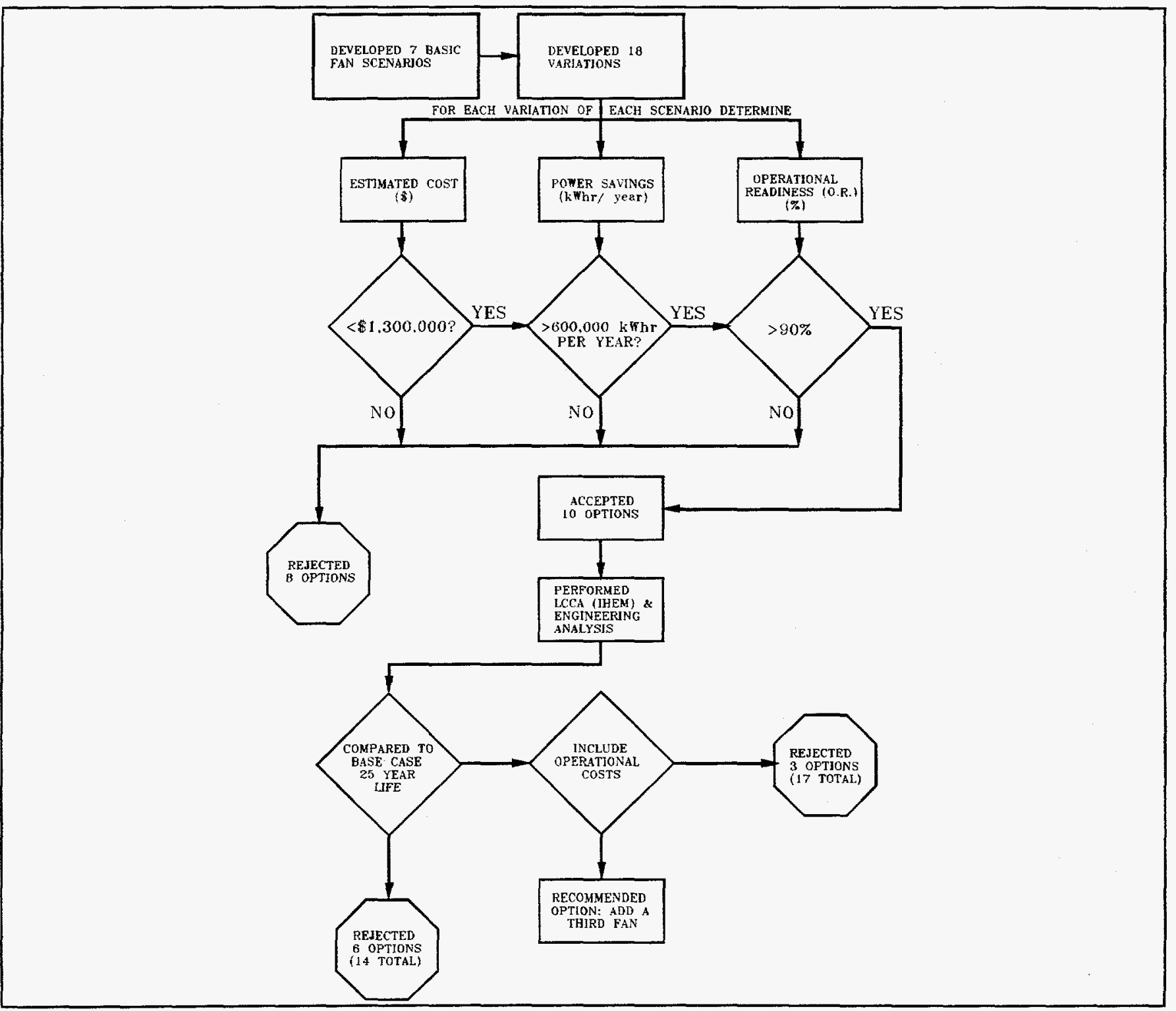

Figure 1. Evaluation Methodology Sequence

Table 1 shows a typical power consumption calculation. The OR requirement was set at $90 \%$. This value was considered the minimum 
acceptable necessary to support the long term operational needs of the WIPP. Table 2 shows a typical fan OR calculation. A fan scenario was eliminated from further consideration if it failed any one of the three criteria. These criteria were used for initial screening to eliminate an unfavorable scenario before additional detailed analysis.

Table 1. Example of Fan Comparison Analyses

\begin{tabular}{|c|c|c|c|c|c|c|}
\hline Base Case & $\begin{array}{l}\text { Operating } \\
\text { Mode }\end{array}$ & $\begin{array}{c}\text { Fan Pressure } \\
\text { (in. w.g.) }\end{array}$ & $\begin{array}{l}\text { Airflow } \\
\text { (ctim) }\end{array}$ & $\begin{array}{c}\text { Fan } \\
\text { Efficiency } \\
(\%)\end{array}$ & $\begin{array}{l}\text { Predicted } \\
\text { Power Consumption }(\mathrm{kWhr} / \mathrm{yr})\end{array}$ & $\begin{array}{l}25 \text { year Life } \\
\text { Cycle Cost }(\$)\end{array}$ \\
\hline \multirow{2}{*}{$\begin{array}{c}\text { Centrifugal with } \\
\text { IVCs }\end{array}$} & Alternate & 4.3 & 330,000 & 37 & $2,571,415$ & \\
\hline & Xormal & 7.3 & 490.000 & 55 & 2.669 .935 & \\
\hline TOTAL & & & & & $5.241,354$ & $12,704,740$ \\
\hline
\end{tabular}

\begin{tabular}{|c|c|c|c|c|c|c|c|c|c|}
\hline $\begin{array}{l}\text { Alternatives } \\
\text { Investigated }\end{array}$ & $\begin{array}{l}\text { Mode of } \\
\text { operation }\end{array}$ & $\begin{array}{c}\text { Fan } \\
\text { Pressure } \\
\text { (in. w.g.) }\end{array}$ & $\begin{array}{l}\text { Airflow } \\
\text { (cfm) }\end{array}$ & $\begin{array}{l}\text { Fan } \\
\text { Eff. } \\
(\%)\end{array}$ & $\begin{array}{c}\text { Predicted } \\
\text { Power } \\
\text { Consumption } \\
\text { (kWhr/yr) }\end{array}$ & $\begin{array}{l}25 \text { year } \\
\text { Life Cycle } \\
\text { Cost }(\$)\end{array}$ & $\begin{array}{l}\text { Annual } \\
\text { Power } \\
\text { Savings } \\
\text { (kWhriyr) }\end{array}$ & $\begin{array}{c}25 \text { Year } \\
\text { LCC } \\
\text { Savings } \\
\text { (\$) }\end{array}$ & $\begin{array}{c}\text { Payback } \\
\text { (years) }\end{array}$ \\
\hline \multirow{2}{*}{$\begin{array}{c}\text { Add Third Fan } \\
\text { (New Fan } \\
\text { wiIVC) }\end{array}$} & Alternate & 4.5 & 330,000 & 42 & $2,255,046$ & & & & \\
\hline & Normal & 8.5 & 245,000 & 83 & 824,996 & & & & \\
\hline \multirow[t]{2}{*}{ Original Fans } & Aiternate & 4.3 & 330,000 & 37 & 431,650 & & & & \\
\hline & Normal & 7.3 & 245,000 & 55 & $1,069,230$ & & & & \\
\hline \multicolumn{5}{|l|}{ TOTAL } & $4,580,621$ & $8,939.677$ & 660,430 & $3,765,063$ & 10 \\
\hline \multirow{2}{*}{$\begin{array}{l}\text { Replace Fans } \\
\text { (two duty } \\
\text { ww/IVCs) }\end{array}$} & Alternate & 4.8 & 330,000 & 56 & $2,131,474$ & & & & \\
\hline & Normal & 10.5 & 490,000 & 83 & $2,018,281$ & & & & \\
\hline \multicolumn{5}{|l|}{ TOTAL } & $4,419,755$ & $8,957,710$ & $1,091,596$ & $3,747,030$ & 12 \\
\hline
\end{tabular}


Table 2: Example of Operational Readiness Calculation. Operational Readiness Calculation for Existing Fan:

Operating Options:

\begin{tabular}{|c|c|c|c|c|}
\hline Fan & 1 & 2 & 3 & 4 \\
\hline \hline 1 & operating & operating & down & down \\
\hline 2 & operating & down & operating & down \\
\hline \hline Normai * & ves & no & no & no \\
\hline Alternate** & ves & yes & yes & no \\
\hline
\end{tabular}

* Normal Mode requires both fans operating

** Alternate Mode requires one of the two fans in operation

Probability of Operating:

\begin{tabular}{|c|c|c|c|c|}
\hline Fan $^{* * *}$ & 1 & 2 & 3 & 4 \\
\hline \hline 1 & 86.5 & 86.5 & 13.5 & 13.5 \\
\hline 2 & 75.2 & 24.8 & 75.2 & 24.8 \\
\hline \hline$(1 \times 2)$ & $65.05 \%$ & $21.45 \%$ & $10.15 \%$ & $3.35 \%$ \\
\hline
\end{tabular}

*** Historical data show fan 1 is available $86.5 \%$, fan 2 at $75.2 \%$.

Normal Mode Operational Readiness: $65.05 \%$

Altemate Mode Operational Readiness: $\underline{96.65 \%}$

\section{Operational Readiness Calculation for Adding a Thind Fan}

Operating Options:

\begin{tabular}{|c|c|c|c|c|}
\hline Fan & 1 & 2 & 3 & 4 \\
\hline \hline 1 & operating & operating & down & down \\
\hline 2 & operating & down & operating & down \\
\hline 3 & operating & operating & operating & operating \\
\hline Normal * $^{*}$ & yes & yes & yes & no \\
\hline Alternate** & yes & yes & yes & yes \\
\hline \hline Fan & 5 & 6 & 7 & 8 \\
\hline \hline 1 & operating & operating & down & down \\
\hline 2 & operating & down & operating & down \\
\hline 3 & down & down & down & down \\
\hline Normal* $^{*}$ & yes & no & no & no \\
\hline Alternate** & ves & yes & yes & no \\
\hline
\end{tabular}

* Normal Mode requires two of three fans operating

**. Alternate Mode requires one of the three fans in operation

Probability of Operating:

\begin{tabular}{|c|c|c|c|c|}
\hline Fan $^{*}$ & 1 & 2 & 3 & 4 \\
\hline \hline 1 & 86.5 & 86.5 & 13.5 & 13.5 \\
\hline 2 & 75.2 & 24.8 & 75.2 & 24.8 \\
\hline 3 & 90.0 & 90.0 & 90.0 & 90.0 \\
\hline \hline$(1 \times 2 \times 3)$ & $58.54 \%$ & $19.31 \%$ & $9.14 \%$ & $3.01 \%$ \\
\hline \hline Fan**** & 1 & 2 & 3 & 4 \\
\hline \hline 1 & 86.5 & 86.5 & 13.5 & 13.5 \\
\hline 2 & 75.2 & 24.8 & 75.2 & 24.8 \\
\hline 3 & 10.0 & 10.0 & 10.0 & 10.0 \\
\hline \hline$(1 \times 2 \times 3)$ & $6.50 \%$ & $2.15 \%$ & $1.02 \%$ & $0.33 \%$ \\
\hline
\end{tabular}

**** Assume new fans have an OR of $90 \%$ each.

Normal Mode Operational Readiness: $\underline{93.49 \%}$

Alternate Mode Operational Readiness: 99.67\% 



\section{LIFE CYCLE COST ANALYSIS}

Supplementary engineering analyses of the preferred scenarios were performed to satisfy the specific requirements of the IHEM application (IHEM requires that cost savings be derived from energy savings and that the project have a simple payback period of less than ten years).

To evaluate the cost effectiveness of each alternative, the Department of Commerce computer program Building Life-Cycle Cost (BLCC Version 4.2-95) was used. This program provides economic analysis of proposed capital investments that are expected to reduce long-term operation costs of buildings or building systems/components. Application of this program toward analysis of the alternative fan scenarios was appropriate. Life cycle cost analyses of all potential fan scenarios were generated and compared to the base case. The BLCC program uses a predetermined (internally programmed) escalation rate for future electric utility costs based on geographic location in the United States. This escalation accounts for (and assumes) common factors that influence electric utilities.

The result of the life cycle cost analysis showed that the use of VFDs resulted in a substantial increase in energy savings as compared to the existing system. However, low energy costs in southeast New Mexico (less than $\$ 0.045 / \mathrm{kWhr}$ ), coupled with the relatively high capital cost of incorporating VFDs, resulted in an unacceptable project payback. This scenario would have saved approximately $43,000,000 \mathrm{kWhrs}$ over 25 years, yet failed to save enough power costs to satisfy the required payback period. A comparison showed that a one cent (or $25 \%$ ) increase in the cost of electricity (per kWhr) resulted in a decrease in the payback period of only 2 years. IHEM funding was eventually dropped from consideration in the study.

Final Life Cycle Cost Analyse were performed on the preferred alternatives. Table 1 also shows an example comparison analyses. Operational impacts associated with each scenario (which were not previously quantified) were included into the analysis at this stage. Each scenario was affected by a base overtime cost (associated with the need to match mining activities with waste disposal activities at full facility throughput), plus overtime cost associated with the unavailability of two main fans to operate in Normal Mode. These costs were applied in the BLCC program in years 7 through 20 of the WIPP expected facility life. This represents the years which simultaneous mining and waste disposal operations is required at full facility throughput. In the worst OR scenario (maintaining the existing system), the OR component resulted in sufficient overtime to justify a second mining crew (at fully burdened costs). For scenarios with increasingly higher $\mathrm{ORs}$, this additional cost became a relatively minor component compared to the base overtime. The addition of these operational considerations had a significant impact on the results of the LCCA.

\section{FINAL CONCLUSIONS}

The final conclusion of the fan study was to install one new single-duty fan of similar size to the existing fans, and to maintain the existing svstem. Any two fans in parallel would be capable of providing Normal Ventilation Mode, and any one fan would be capable of providing Alternate Ventilation Mode. The new fan system would be designed with a 25 year life and be suitable to endure weathering in a corrosive salt-and-moisture environment. The system would provide redundant fans available to achieve Norma? 
Ventilation Mode. The new fan would be run $100 \%$ of its available time in order to maximize the system efficiency and OR. The existing fans will be overhauled on a periodic basis depending on their operational utilization and rate of deterioration. The new system would provide the underground ventilation system with a volumetric efficiency of approximately $80-85 \%$ during normal mode, and $55-60 \%$ during alternate mode of operation. The OR for Normal Ventilation Mode would be increased from $65 \%$ to $96 \%$. IVCs were ultimately chosen over VFDs because of capital cost considerations. The new system has a LCCA savings of $\$ 3,765,000$ compared to the base case, and a discounted payback of approximately 10 years.

\section{SUMMARY}

The underground ventilation main fan study provided an opportunity to analyze multiple fan replacement scenarios on a comparative basis prior to making a final recommendation. The use of pass/fail criteria for capital cost, $O R$, and power consumption savings enabled unfavorable alternatives to be eliminated early in the process without completing extensive economic analysis on each, thus requiring less engineering effort for a more complete study. The use of the Building Life-Cycle Cost (BLCC Version 4.2-95) program allowed the more favorable alternatives to be analyzed and compared to the base case in order to understand the long term costs for each alternative. The result of this study is that a fan system was proposed which will support the operational needs of the underground facility, and provide a reasonable payback period while optimizing the use of existing site resources.

Processing and final preparation of this paper was performed by Westinghouse Electric Corporation, Waste Isolation Division, the management and operating contractor for the Waste Isolation Pilot Plant under U.S. Department of Energy contract number DEAC04-86AL31950.This document has been submitted as required to:

Office of Scientific and Technical Information

P. O. Box 62

Oak Ridge, TN 37831

(615) 576-8401

Additional Information about this document may be obtained by calling (800) 336-9477. Copies may be obtained by contacting the National Technical Information Service, US Department of Commerce, 5285 Port Royal Road, Springfield, VA 22101. 